\title{
ANALISIS PENGETAHUAN KADER TENTANG PERAN DAN FUNGSI KADER DI DESA CIKUNIR KECAMATAN SINGAPARNA KABUPATEN TASIKMALAYA TAHUN 2016
}

\author{
Fenty Agustini, S.ST, M.Kes
}

\section{A. ABSTRAK}

Kader merupakan tenaga masyarakat yang dianggap paling dekat dengan masyarakat. Departemen kesehatan membuat kebijakan mengenai pelatihan untuk kader yang dimaksudkan untuk meningkatkan pengetahuan, menurunkan angka kematian ibu dan angka kematian bayi. Keaktifan kader dalam kegiatan akan meningkatkan keterampilan karena selalu hadir dalam kegiatan posyandu. Berdasarkan hasil studi pendahuluan sebagian besar kader tidak menjalankan tugas pokok dan fungsi sebagai seorang kader. Hal ini menunjukkan masih kurangnya pengetahuan kader tentang peran dan fungsi kader. Tujuan penelitian adalah untuk mengetahui tingkat pengetahuan kader tentang peran dan fungsi kader di Desa Cikunir Kecamatan Singaparna Kabupaten Tasikmalaya Tahun 2016.

Penelitian ini merupakan penelitian deskriptif kuantitatif dilaksanakan di Desa Cikunir Kecamatan Singaparna Kabupaten Tasikmalaya dengan jumlah sampel 45 responden dan tehnik pengambilan sampel menggunakan teknik accidental sampling. Instrumen yang digunakan dalam pengumpulan data penelitian ini adalah kuesioner dan menggunakan Analisis data univariat.

Hasil penelitian tersebut yaitu tingkat pengetahuan kader tentang peran dan fungsi kader di Desa Cikunir Kecamatan Singaparna Kabupaten Tasikmalaya Hasil yang diperoleh dari penelitian ini bahwa tingkat pengetahuan kader tentang peran dan fungsi kader yaitu di kategori baik ada 17 responden (37,8\%), dan kategori kurang 28 responden $(62,2 \%)$.

Berdasarkan hasil penelitian tersebut dapat disimpulkan tingkat pengetahuan kader tentang peran dan fungsi kader di Desa Cikunir Kecamatan Singaparna sebagian besar pada kategori kurang yaitu 28 responden (62,2\%).

\section{Kata Kunci posyandu}

\section{: pengetahuan kader tentang peran dan fungsi kader}




\section{B. PENDAhuluan}

Salah satu upaya mewujudkan masyarakat Indonesia yang sehat adalah dengan mengikut sertakan masyarakat atau kader yang bersedia secara sukarela terlibat dalam masalah-masalah kesehatan (Yulifah dkk, 2009).Posyandu merupakan milik masyarakat maka pelaksanaan kegiatan posyandu agar hasilnya baik perlu peran serta masyarakat itu sendiri khususnya keaktifan kader posyandu. Kader posyandu dipilih oleh pengurus posyandu dari anggota masyarakat yang bersedia, mampu dan memiliki waktu untuk menyelenggarakan kegiatan posyandu. Kader posyandu menyelenggarakan kegiatan posyandu secara sukarela. Namun dalam pelaksanaan kegiatan posyandu ada hambatan-hambatan, salah satunya adalah hambatan dari kader diantaranya kurang aktifnya kader-kader posyandu (Depkes RI, 2006).

Melalui sistem pengkaderan dengan pelatihan, penyuluhan, dan bimbingan dapat menumbuhkan sikap mandiri sehingga mampu menggali dan memanfaatkan sumber daya yang tersedia serta menumbuhkan dan memecahkan masalah yang dihadapi guna mencapai pelayanan yang optimal (Depkes RI, 2006)

Kader merupakan tenaga masyarakat yang dianggap paling dekat dengan masyarakat.Departemen kesehatan membuat kebijakan mengenai pelatihan untuk kader yang dimaksudkan untuk meningkatkan pengetahuan, menurunkan angka kematian ibu dan angka kematian bayi.Para kader kesehatan masyarakat seyogyanya memiliki latar belakang pendidikan yang cukup sehingga memungkinkan mereka untuk membaca, menulis dan menghitung secara sederhana (Meilani dkk, 2009).

Untuk itu diperlukan kader yang baik, yang dapat menyumbangkan tenaga dan pikirannya untuk meningkatkan kesehatan masyarakat.Petugas kesehatan hanya mengawasi dan membantu upaya yang bukan wewenang kader posyandu.Pada kenyataanya pada setiap pelaksanaan kegiatan posyandu peran petugas kesehatan dan bidan lebih menonjol (Depkes RI, 2006). Keaktifan kader dalam kegiatan akan meningkatkan keterampilan karena selalu hadir dalam kegiatan posyandu, kader akan mendapatkan keterampilan dari pembinaan petugas maupun dengan belajar dari teman sekerjanya. Pengetahuan sangat penting dalam memberikan pengaruh terhadap sikap dan tingkah laku kader terhadap pelayanan posyandu (Meilani dkk, 2011).

Berdasarkan hasil studi pendahuluan sebagian besar kader tidak menjalankan tugas pokok dan fungsi sebagai seorang kader. Hal ini menunjukkan masih kurangnya pengetahuan kader tentang peran dan fungsi kader. Berdasarkan latar belakang di atas, penulis tertarik melakukan penelitian dengan judul "Analisis Pengetahuan Kader tentang Peran dan Fungsi Kader di Desa Cikunir Kecamatan Singaparna 
Kabupaten Tasikmalaya Tahun 2016".

\section{METODOLOGI}

\section{Jenis Penelitian}

Penelitian ini menggunakan penelitian deskriptif kuantitatif. Pada penelitian ini menggambarkan tentang "Analisis Pengetahuan Kader tentang Peran dan Fungsi Kader di Desa Cikunir Kecamatan Singaparna Tahun 2016".

\section{Populasi dan Sampel}

Populasi dalam penelitian ini adalah seluruh kader yang aktif di Desa Cikunir Kecamatan Singaparna sedabgkan pengambilan sample dengan cara accidental sampling berjumlah 45 kader.

3. Variabel Penelitian

Penelitian ini menggunakan variable tunggal yaitu pengetahuan kader tentang peran dan fungsi kader.

\section{Lokasi dan Waktu Penelitian}

Penelitian ini dilakukan di Desa Cikunir Kecamatan Singaparna Kabupaten Tasikmalaya. Penelitian dilaksanakan pada bulan Juni sampai Desember 2016.

5. Prosedur Pengumpulan Data

Teknik pengumpulan data diperoleh terdiri dari Data primer adalah data dikumpulkan sendiri oleh peneliti data primer diperoleh dari hasil pengisian kuesioner

6. Instrumen Penelitian

Dalam penelitian ini instrumen penelitian atau alat yang digunakan untuk pengambilan data adalah kuesioner.

\section{Pengolahan Data dan Analisis Data}

1. Pengolahan Data

Pengolahan data dalam suatu penelitian merupakan langkah yang sangat penting dan mutlak dilakukan, sehingga data tersebut dapat memberikan makna dan memenuhi tujuan penelitian, serta dapat ditarik kesimpulan.

a. Editing data

Editing adalah menyeleksi atau memeriksa kembali data yang telah didapat dari lembar kuesioner apakah lengkap atau tidak.

b. Coding data

Coding yaitu melakukan pengodean pada data agar tidak terjadi kekeliruan dalam melakukan tabulasi data.

c. Tabulating data

Pengelompokkan data ke dalam tabel tertentu menurut nilai yang dihasilkan sesuai dengan tujuan penelitian.

d. Entrying data

Memasukan data ke dalam Komputer yang ditampilkan baik berbentuk tabel ataupun grafik.

2. Analisis Data

Analisa data yang akan digunakan adalah analisa secara univariat. Analisis univariat dilakukan untuk melihat distribusi frekuensi dari variabel dependents. Dibuat tabel distribusi frekuensi dari semua sebaran variabel yang terdapat dalam penelitian ini. Analisa univariat dilakukan dengan menggunakan rumus distribusi frekuensi. 


\section{HASIL PENELITIAN}

1. Umur

Tabel Distribusi Frekuensi Karakteristik Responden Berdasarkan Umur

\begin{tabular}{llccc}
\hline No & Umur & Frekuensi & Persentase (\%) \\
\hline 1 & 20-35 Tahun & 10 & 22,2 \\
2 & >35 Tahun & 35 & 77,8 \\
& \multicolumn{2}{c}{ Jumlah } & $\mathbf{4 5}$ & $\mathbf{1 0 0}$ \\
\hline
\end{tabular}

Dari tabel diatas terlihat bahwa sebagian besar kader berusia lebih dari 35 Tahun yaitu sebanyak $77,8 \%$.

Tabel Tabulasi Silang Antara Pengetahuan dengan Umur

\begin{tabular}{|c|c|c|c|c|c|c|}
\hline \multirow{3}{*}{ Umur } & \multicolumn{4}{|c|}{ Pengetahuan } & \multirow{3}{*}{ Jumlah } & \multirow{3}{*}{$\%$} \\
\hline & \multicolumn{2}{|c|}{ Baik } & \multicolumn{2}{|c|}{ Kurang } & & \\
\hline & $\mathbf{F}$ & $\%$ & $\mathbf{F}$ & $\%$ & & \\
\hline$<20-35$ Tahun & 1 & 5,8 & 9 & 32,1 & 10 & 22,2 \\
\hline$>35$ Tahun & 16 & 94,2 & 19 & 67,9 & 35 & 77,8 \\
\hline Jumlah & 17 & 100 & 28 & 100 & 45 & 100 \\
\hline
\end{tabular}

2. Pendidikan

Tabel Distribusi Frekuensi Karakteristik Responden Berdasarkan Tingkat Pendidikan

\begin{tabular}{lllcc}
\hline No & & Pendidikan & Frekuensi & Persentase (\%) \\
\hline 1 & Rendah & & 28 & 62,2 \\
2 & Menengah & & 15 & 33,3 \\
3 & Tinggi & & 2 & 4,5 \\
& & Jumlah & $\mathbf{4 5}$ & $\mathbf{1 0 0}$ \\
\hline
\end{tabular}

Dari tabel diatas terlihat bahwa sebagian besar ibu memiliki tingkat pendidikan rendah yaitu sebanyak $62,2 \%$.

Tabel Tabulasi Silang Antara Tingkat Pengetahuan dengan Pendidikan

\begin{tabular}{|c|c|c|c|c|c|c|}
\hline \multirow{3}{*}{ Pendidikan } & \multicolumn{4}{|c|}{ Pengetahuan } & \multirow{3}{*}{ Jumlah } & \multirow{3}{*}{$\%$} \\
\hline & \multicolumn{2}{|c|}{ Baik } & \multicolumn{2}{|c|}{ Kurang } & & \\
\hline & $\mathbf{F}$ & $\%$ & $\mathbf{F}$ & $\%$ & & \\
\hline Rendah & 11 & 64,7 & 17 & 60,7 & 28 & 62,2 \\
\hline Menengah & 4 & 23,5 & 11 & 39,3 & 15 & 33,3 \\
\hline Tinggi & 2 & 11,8 & 0 & 0 & 2 & 4,5 \\
\hline Jumlah & 17 & 100 & 28 & 100 & 45 & 100 \\
\hline
\end{tabular}




\section{E. PEMBAHASAN}

Berdasarkan penelitian yang telah di lakukan di Desa Cikunir Kecamatan Singaparna dengan jumlah responden 45 kader. Hasil yang diperoleh dari penelitian ini bahwa tingkat pengetahuan kader tentang peran dan fungsi kader yaitu di kategori baik ada 17 responden $(37,8 \%)$, dan kategori kurang 28 responden $(62,2 \%)$.

Dari hasil penelitian kader yang berpengetahuan cukup sebagian besar kader telah memahami pengertian sebagai kader yaitu sebagai penggerak atau promotor kesehatan, peran kader dalam posyandu maupun di luar posyandu terutama pengamat terhadap masalah kesehatan masyarakat, dan fungsi kader pada kegiatan posyandu. Adapun yang belum dimengerti kader yaitu tugas sebagai kader terutama tugas diluar posyandu.

Kader yang berpengetahuan baik sebagian basar kader telah mengenai pengertian kader, peran kader di dalam maupun di luar posyandu, fungsi kader, tugas - tugas kader, maupun strategi eksistensi kader. Selain itu kader yang berpengetahuan kurang rata - rata kader telah mengerti tentang pengertian kader yaitu kader merupakan orang yang dekat dengan masyarakat, fungsi kader di dalam posyandu. Akan tetapi kurang memahami tentang peran kader terutama di luar masyarakat, tugas-tugas kader maupun strategi eksistensi kader.

Pengertian kader kesehatan masyarakat adalah laki-laki atau wanita yang dipilih oleh masyarakat dan dilatih untuk mengenai masalah-masalah kesehatan perseorangan maupun masyarakat serta untuk bekerja dalam hubungan yang amat dekat tempat-tempat pemberian pelayanan kesehatan (Meilani dkk, 2009). Sedangkan menurut Yulifah danYuswanto(2009) Kader kesehatan adalah tenaga sukarela yang dipilih oleh masyarakat dan bertugas mengembangkan masyarakat.

Dalam hal ini kader disebut juga sebagai penggerak atau promotor kesehatan.

Peran dan fungsi kader sebagai pelaku penggerakan masyarakat menurut Meilani dkk (2009) adalah Perilaku Hidup Bersih dan Sehat (PHBS), pengamatan terhadap masalah kesehatan di desa, upaya penyehatan lingkungan, peningkatan kesehatan ibu, bayi, dan anak balita, pemasyarakatan keluarga sadar gizi (Kadarzi).

Fungsi Kader menurut Depkes RI (2010) adalah melakukan pencatatan, memantau dan evaluasi kegiatan Poskesdes bersama Bidan, mengembangkan dan mengelola UKBM (PHBS, Kesling, KIBB-Balita, Kadarzi, Dana Sehat, TOGA, dll), mengidentifikasi dan melaporkan kejadian masyarakat yang berdampak terhadap kesehatan masyarakat (surveilance berbasis masyarakat), pemecahan masalah bersama masyarakat.

Tugas-tugas kader dalam rangka menyelenggarakan posyandu dibagi menjadi tiga kelompok, yaitu sebagai berikut menurut Yulifah dan Yuswanto (2009) adalah tugas kader pada saat persiapan hari buka posyandu, meliput menyiapkan alat penimbangan bayi, Kartu Menuju Sehat (KMS), alat peraga, alat pengukur lingkar lengan atas untuk ibu hamil dan bayi/anak, obat-obatan yang dibutuhkan (misalnya, tablet tambah darah/zat besi, vitamin $\mathrm{A}$, oralit), bahan atau materi penyuluhan, mengundang dan menggerakkan masyarakat, yaitu dengan memberitahu ibu-ibu untuk datang ke posyandu, serta melakukan pendekatan dengan tokoh-tokoh masyarakat yang dapat 
memotivasi masyarakat untuk datang ke posyandu, menghubungi kelompok kerja (pokja) posyandu, yaitu menyampaikan rencana kegiatan kepada kantor desa dan meminta untuk memastikan apakah petugas dapat hadir pada hari buka posyandu, melaksanakan pembagian tugas di antara kader posyandu baik untuk persiapan maupun pelaksaan kegiatan. Tugas kader pada hari buka posyandu disebut juga dengan tugas pelayanan pada lima meja. Tugas kader di luar posyandu kader ditunjuk oleh masyarakat dan biasanya kader melaksanakan tugas-tugas kader kesehatan masyrakat yang secara umum. Pertolongan pertama pada kecelakaan dan penanganan penyakit yang ringan, melakukan pengobatan sederhana, pemberian motivasi dan saran-saran pada ibu - ibu sebelum dan sesudah melahirkan, pemberian motivasi dan saran - saran tentang perawatan anak, memberikan dan motivasi dan peragaan tentang gizi (program UPGK), program penimbangan balita dan pemberian makanan tambahan, pemberian motivasi tentang imunisasi dan bantuan pengobatan, pemberian motivasi $\mathrm{KB}$, membagikan alat - alat $\mathrm{KB}$, pemberian motivasi tentang sanitasi lingkungan, kesehatan perorangan dan kebiasaan sehat secara umum, pemberian motivasi tentang penyakit menular seksual, pencegahan dan perujukan, pemberian motivasi tentang perlunya follow up pada penyakit menular dan perlunya memastikan diagnosis, penanganan dalam mencegah penyakit menular, membantu kegiatan di klinik, merujuk penderita ke puskesmas atau ke rumah sakit, membina kegiatan UKS secara teratur, mengumpulkan data yang dibutuhkan oleh puskesmas, membantu pencatatan dan pelaporan. Berdasarkan Meilani dkk (2009), perlu adanya srategi agar mereka dapat selalu eksis membantu masyarakat di bidang kesehatan. Beberapa upaya yang dapat dilaksanakan adalah refresing kader posyandu pada saat posyandu telah selesai dilaksanakan, oleh bidan desa maupun petugas lintas sektor yang mengikuti kegiatan posyandu, adanya paguyuban kader posyandu tiap desa dan dilaksanakan pertemuan rutin tiap bulan secara bergilir di setiap posyandu, revitalisasi kader posyandu baik tingkat desa kecamatan. Di mana semua kader diundang dan diberikan penyegaran materi serta hiburan dan bisa juga diberikan rewards, pemberian rewards rutin misalnya berupa kartu berobat gratis ke puskesmas untuk kader dan keluarganya dan juga dalam bentuk materi yang lain yang diberikan setiap tahun.

Dari pembahasan di atas dapat disimpulkan sebagian besar kader berpengetahuan kurang mengenai peran dan fungsi kader di dalam posyandu maupun di luar posyandu tetapi kader kurang memahami tentang tugas - tugas kader terutama di luar posyandu seperti pemberian dan pemahaman tentang $\mathrm{KB}$, pencegahan dan penanganan pada penyakit menular seksual di dalam masyarakat. Oleh karena itu sebaiknya kualitas pelayanan kader kesehatan dapat ditingkatkan dengan cara memberikan penyegaran materi mengenai kesehatan dan pertemuan rutin setiap bulannya ataupun lomba kesehatan lingkungan untuk meningkatkan kader dalam melakukan peran dan fungsi maupun tugas kader di dalam posyandu maupun di masyarakat sehingga dapat meningkatkan kualitas kesehatan masyarakat. Adapun faktor-faktor yang mempengaruhi pengetahuan kader tersebut adalah umur dan pendidikan kader. 


\section{F. SIMPULAN DAN SARAN}

Berdasarkan hasil penelitian dapat disimpulkan bahwa sebagian besar tingkat pengetahuan kader tentang peran dan fungsi kader yaitu di kategori kurang yaitu 28 responden (62,2\%).

Berdasarkan hasil penelitian mengenai Tingkat Pengetahuan Kader Tentang Peran dan Fungsi Kader di Desa Cikunir maka saran yang dapat peneliti sampaikan adalah:

\section{Bagi Kader}

Diharapkan dengan adanya penelitian ini, para kader lebih aktif mencari informasi melalui media cetak, tenaga kesehatan, sebaiknya ikut serta dalam menerapkan dan melaksanakan ilmu yang diperoleh terutama peran dan fungsi kader di dalam posyandu maupun di luar posyandu.

2. Bagi Institusi

a. Desa Cikunir

Diharapkan bagi Desa dapat membimbing, mengarahkan para kader dengan memberikan penyegaran materi kesehatan, pertemuan rutin, dan memotivasi kader dalam melaksanakan peran dan fungsi kader di posyandu maupun di luar posyandu.

b. STIKes Respati Tasikmalaya

Diharapkan akan lebih mengembangkan penelitian lebih lanjut mengenai peran dan fungsi kader sehingga dapat dijadikan referensi dan bahan bacaan.

c. Bagi peneliti lain

Diharapkan dapat dilakukan penelitian lebih lanjut tentang peran dan fungsi kader dengan metode penelitian yang berbeda, variabel yang berbeda, instrumen yang berbeda, sehingga akan diperoleh hasil yang lebih baik.

\section{G. DAFTAR PUSTAKA}

Andriani, D. 2009. Pengetahuan Kader tentang Posyandu di Posyandu Ngudi Santoso DonohudanNgemplak Boyolali Tahun 2009. Jawa Tengah : Bagian Kependidikan dan Biostatistik Falkutas Kesehatan Universitas Sebelas Maret.

Arikunto, S. 2010. Prosedur Penelitian Suatu Pendekatan Praktek. Jakarta: PT.

Rineka Cipta.

Depkes RI. 2006. Buku Pegangan Kader dan Toma.Jakarta : Buku Pedoman Desa Siaga Aktif. Jakarta : Depkes RI .2006.Kurikulum

Pelatihan Desa Siaga. Jakarta : Depkes RI

Siaga. Jakarta : Depkes RI 2006.Modul Desa

Ghozali, I. 2005. Aplikasi Analisis Multivariate dengan Program SPSS.

Semarang: Badan Penerbit Universitas Diponegoro.

Hidayat,A.A.2009.MetodePeneli tianKeperawatan

Jakarta: Salemba Medika.

Mahmud, H. 2011. Metode Penelitian Pendidikan. Bandung: CV. Pustaka Setia.

Meilani, N. N. Setyawati. D. Estiwidani. Sumarah. 2009. Kebidanan Komunitas.

Yogyakarta : 2009

Notoatmodjo, S. 2007. Kesehatan Masyarakat Ilmu dan Seni. Jakarta : Rineka Cipta. 2010. Metodologi

Penelitian Kesehatan. Jakarta : Rineka Cipta.

Nursalam. 2008. Konsep dan Penerapan Metodologi Ilmu Keperawatan. Jakarta:

Salemba Medika 
Riwidikdo, H. 2010. Statistik

Kesehatan. Yokyakarta : Mitra Cendekia Press.

Tyas,I.A. 2010.

Pengetahuan Kader tentang

Posyandu di Purwosari

Surakarta Tahun 2010. Jawa

Tengah : Bagian Kependidikan

dan Biostatistik Falkutas

Kesehatan Universitas Sebelas

Maret.WHO. 2002. Kader

Kasehatan Masyarakat (The

Community Health Worker).
Jakarta : EGC

Yulifah, R. T.J.A. Yuswanto.

2009. Asuhan Kebidanan

Komunitas.Jakarta :

Penerbit Salemba Medik 